\title{
Impact of Bile Exposure Time on Organ/space Surgical Site Infections After Pancreaticoduodenectomy
}

\author{
YU KUMAGAI, SHUICHI FUJIOKA, TAIGO HATA, TAKEYUKI MISAWA, \\ HIROAKI KITAMURA, KENEI FURUKAWA, YUICHI ISHIDA and KATSUHIKO YANAGA \\ Department of Surgery, Jikei University School of Medicine, Tokyo, Japan
}

\begin{abstract}
Background/Aim: Organ/space surgical site infections (SSIs) are critical complications of pancreaticoduodenectomy. We investigated the impact of the time between division of the common hepatic duct and completion of biliary reconstruction [bile exposure (BE) time] on the occurrence of post-pancreaticoduodenectomy organ/space SSI. Patients and Methods: Sixty-one patients who underwent pancreaticoduodenectomy were retrospectively studied. The impact of perioperative variables and BE time on organ/space SSI occurrence was analyzed. Results: Organ/space SSIs occurred in 17 patients (28\%). Patients were divided into two groups according to BE time. The incidence of organ/space SSIs was significantly higher in the long BE time group than in the short BE time group (42\% versus $13 \%, p=0.0127)$. Multivariate analysis revealed that long BE times [odds ratio $(O R)=4.8 ; p=0.0240]$ and soft pancreatic texture $(O R=16.5$; $p=0.0106)$ were independent risk factors for organ/space SSIs. Conclusion: Long BE time is a risk factor for postpancreaticoduodenectomy organ/space SSIs. Shortening BE time may reduce organ/space SSI occurrence.
\end{abstract}

Despite advances in surgical techniques, pancreaticoduodenectomy is a complex procedure that carries a high risk of postoperative infectious complications, including surgical site infections (SSIs). During the last decade, SSIs occur in up to $30 \%$ of patients (1-7). Organ/space SSIs contribute significantly to increased rates of sepsis, prolonged hospital stays, readmission, and increased costs for patient care $(8,9)$.

This article is freely accessible online.

Correspondence to: Shuichi Fujioka, MD, Department of Surgery, Kashiwa Hospital, Jikei University School of Medicine, 163-1 Kashiwashita, Kashiwashi, Chiba 277-8567, Japan. Tel: +81 471641111 Ext. 3421, Fax: +81 471633488, e-mail: sfujioka@jikei.ac.jp

Key Words: Pancreaticoduodenectomy, organ/space SSI, bile, biliary reconstruction.
Recent reports suggest that long operation time is associated with intraoperative bacterial contamination, especially via biliary pathogens, which can lead to postpancreatico-duodenectomy organ/space SSIs $(1,2,10)$. Although bile is usually sterile, and even when the bile duct shows no signs of microbial colonization (11), preoperative endoscopic retrograde cholangiopancreatography and biliary drainage can result in bile colonization (bacterobilia) at the time of surgery $(12,13)$. Additionally, while Enterococcus species are commonly isolated in intraoperative bile cultures $(9,10,14)$, the use of antibiotics with anti-enterococcal spectrum is desirable for prophylactic antibiotics before pancreaticoduodenectomy in case of preoperative biliary stenting $(10,14)$.

Moreover, although post-pancreaticoduodenectomy organ/ space SSIs may, in part, result from intraoperative bacterobilia, its clinical relevance and direct association with postoperative complications remain controversial $(1,2,15-18)$. This study aimed to clarify the impact of the time between the division of common hepatic duct to completion of biliary reconstruction (BR) [bile exposure (BE) time] on the occurrence of postpancreaticoduodenectomy organ/space SSIs.

\section{Patients and Methods}

Study design and operation procedure. We retrospectively reviewed patients who underwent pancreaticoduodenectomy for the treatment of benign and malignant peri-ampullary lesions at the Jikei Kashiwa Hospital (Kashiwa City, Japan) between January 2015 and October 2017. Preoperative biliary drainage (PBD) was performed for patients with obstructive jaundice. The internal drainage techniques used for these patients were endoscopic retrograde biliary drainage and endoscopic nasogastric biliary drainage. During surgery, bile juice was sampled and cultured when the common hepatic duct was transected. The texture of the pancreas (soft or hard) was determined by surgeon according to the intraoperative pancreas palpation. All patients underwent modified Child's reconstruction with subtotal stomach-preserving pancreaticoduodenectomy. At the end of the operation, the peritoneal cavity was irrigated using $7,000 \mathrm{ml}$ of normal saline (7 washings of $1,000 \mathrm{ml}$ each) with a clean suction apparatus. Prior to the lavage, surgical globes were changed. 
Table I. Baseline characteristics of patients.

\begin{tabular}{lc}
\hline Patient characteristics & $\begin{array}{c}\text { Number of patients, } \mathrm{n}(\%) \\
(\mathrm{N}=61)\end{array}$ \\
\hline Age (years) ${ }^{\dagger}$ & $70(41-83)$ \\
Gender (male:female) & $37: 24$ \\
Type of disease & \\
Pancreatic head carcinoma & $28(46)$ \\
Bile duct carcinoma & $9(15)$ \\
IPMN & $6(10)$ \\
Ampullary carcinoma & $6(13)$ \\
Others & $10(16)$ \\
Pancreatic parenchyma & \\
Soft & $38(62)$ \\
Hard & $23(38)$ \\
Biliary drainage & \\
Yes & $25(41)$ \\
No & $36(59)$ \\
\hline
\end{tabular}

$\dagger$ Values represent median (range). IPMN, Intraductal papillary mucinous neoplasm.

At the end of procedure, closed drains were placed anterior to pancreatico-jejunal anastomoses and dorsal to choledocho-jejunal anastomoses in all patients. Prophylactic antibiotics were administered routinely within the perioperative period. One gram of Cefmetazole (second-generation cephalosporin) was administered intravenously within $1 \mathrm{~h}$ before surgery and at approximately $3-\mathrm{h}$ intervals intraoperatively. Cefmetazole administration was continued 3 times per day, for $48 \mathrm{~h}$ postoperatively.

The presence of SSIs, including incisional and organ/space SSIs, was determined according to the Centers for Disease Control and Prevention's national nosocomial infections surveillance system (19). BE time was defined as the time between common hepatic duct division and BR completion, which was obtained from each patient's time records in the operating room. BE time and other continuous variables were divided into two (long and short) groups according to the cut-off value obtained by Receiver Operating Characteristic (ROC) curve analysis for univariate and multivariate analysis. Patients provided written informed consent prior to undergoing surgery. This study was conducted in accordance with the Declaration of Helsinki and with the approval of the Ethics Committee of the Jikei University School of Medicine [approval no. 30-150 (9171)].

Statistical analysis. To evaluate the relationship between each categorized factor in terms of BE time, a univariable analysis was conducted using the $\chi^{2}$ test or Fisher's exact test, as appropriate. A logistic regression model and ROC curve analysis were used to assess the predictive characteristics of $\mathrm{BE}$ time with potential confounder variables. A $p$-value of $<0.02$ in the univariate analysis or a $p$-value of $<0.05$ in the logistic regression analysis was judged statistically significant. All statistical analyses were performed using Stat View-J 5.0 (Avacus Concepts Inc., Berkeley, CA, USA) and MedCalc 8.1 software (MedCalc Software, Mariakerke, Belgium).

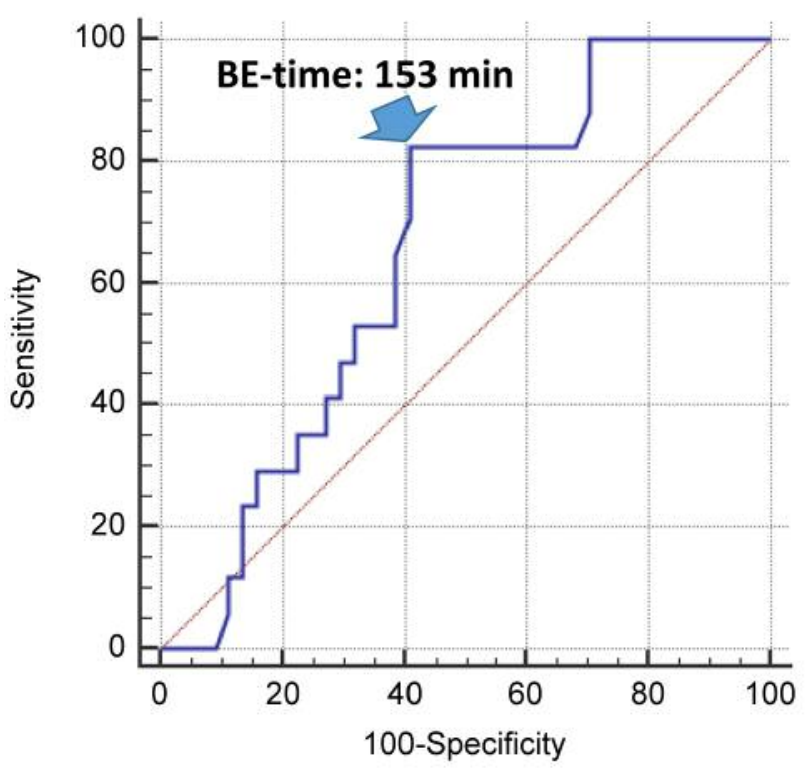

Figure 1. Receiver operating characteristic (ROC) curve analysis predicted the value of bile exposure (BE)-time for occurrence of organ/space surgical site infection (SSI).

\section{Results}

A total of 61 consecutive patients who underwent open pancreaticoduodenectomy were included in this study. Patient characteristics and perioperative variables are listed in Table I. The median BE time was 157 min (range=76-366; mean= $174 \pm 69)$ and patients were divided into two groups; the long ( $\geq 153 \mathrm{~min} ; \mathrm{n}=31$ ) and short $(<152 \mathrm{~min} ; \mathrm{n}=30$ ) BE time groups. Of the 61 patients, 17 (27.9\%) developed organ/space SSIs. ROC curve analysis indicated BE time achieved considerably high sensitivity (82\%) and specificity (59\%), for the prediction of organ/space SSI occurrence (Area under the curve: 0.66; 95\% confidence interval $=0.52-0.77 ; p=0.0299$; Figure 1 ).

There was no significant relation between patient's characteristics and organ/space SSI (Table II). On univariate analysis for perioperative variables, soft pancreatic texture $(p=0.0120)$ and long BE times $(p=0.0127)$ were significantly associated with the occurrence of organ/space (Table III). By multivariate analysis using these two variables, soft pancreatic texture $[p=0.0106$; Odds ratio $(\mathrm{OR})=16.5)$ and long $\mathrm{BE}$ times $(p=0.0240 ; \mathrm{OR}=4.8)$ were independently related to the occurrence of organ/space SSIs (Table IV).

\section{Discussion}

The development of post-pancreaticoduodenectomy SSIs is a common and serious complication. Studies have shown that prolonged operation times result in increased wound susceptibility to bacterial infection, thereby causing the 
Kumagai et al: BE-time and Post-pancreaticoduodenectomy Organ/Space SSIs

Table II. Comparison of the occurrence of organ/space surgical site infection (SSI) and patient characteristics.

\begin{tabular}{|c|c|c|c|c|}
\hline \multirow[t]{2}{*}{ Patient characteristics } & \multirow[t]{2}{*}{ Ratio } & \multicolumn{2}{|c|}{ Organ/space SSI } & \multirow[t]{2}{*}{$p$-Value } \\
\hline & & Yes $(n=17)$ & No $(n=44)$ & \\
\hline Age & $\geq 79,<78$ & $5: 12$ & $10: 34$ & 0.7412 \\
\hline Gender & male:female & $13: 4$ & $24: 20$ & 0.1160 \\
\hline Body mass index $\left(\mathrm{kg} / \mathrm{m}^{2}\right)$ & $\geq 18.2,<18.1$ & $13: 4$ & $28: 16$ & 0.3819 \\
\hline Preoperative $\mathrm{HbA} 1 \mathrm{C}(\%)$ & $\geq 6.2,<6.1$ & $9: 8$ & $13: 31$ & 0.0880 \\
\hline Preoperative serum albumin $(\mathrm{g} / \mathrm{dl})$ & $\geq 4.2,<4.1$ & $7: 10$ & $22: 22$ & 0.5361 \\
\hline Primary disease & & & & 0.0619 \\
\hline Pancreatic head carcinoma & & 4 & 24 & \\
\hline Bile duct carcinoma & & 4 & 5 & \\
\hline Ampullary carcinoma & & 5 & 3 & \\
\hline IPMN & & 2 & 45 & \\
\hline Others & & 2 & 8 & \\
\hline
\end{tabular}

Table III. Comparison of the occurrence of organ/space surgical site infection (SSI) and perioperative findings.

\begin{tabular}{|c|c|c|c|c|}
\hline \multirow[t]{2}{*}{ Perioperative findings } & \multirow[t]{2}{*}{ Ratio } & \multicolumn{2}{|c|}{ Organ/space SSI } & \multirow[t]{2}{*}{$p$-Value } \\
\hline & & Yes $(n=17)$ & No $(n=44)$ & \\
\hline Duration of operation & $\geq 430 \mathrm{~min}:<429 \min$ & $6: 11$ & $24: 20$ & 0.1775 \\
\hline Intraoperative blood loss & $\geq 591 \mathrm{~g}:<590 \mathrm{~g}$ & $8: 9$ & $23: 21$ & 0.7150 \\
\hline Superior mesenteric-portal vein resection & Yes:no & $2: 15$ & $14: 30$ & 0.1930 \\
\hline Preoperative biliary drainage & Yes:no & $9: 8$ & $16: 28$ & 0.2379 \\
\hline Intraoperative bile culture & Infected: not infected & $7: 10$ & $12: 32$ & 0.2931 \\
\hline Operator's level of expertise & Instructor: trainee & $6: 11$ & $12: 32$ & 0.5380 \\
\hline Pancreatic texture & Soft:hard & $16: 1$ & $22: 22$ & 0.0120 \\
\hline Bile exposure time group & $\geq 153 \min :<152 \min$ & $13: 4$ & $18: 26$ & 0.0127 \\
\hline
\end{tabular}

development of organ/space SSIs $(2,20,21)$. Studies have also reported that PBD increases the incidence rate of biliary infection and organ/space SSIs $(15,17,22,23)$. In fact, biliary pathogens match with those identified in the abdominal abscesses of $50-100 \%$ of patients who have undergone postPBD pancreaticoduodenectomy $(15,24-26)$. While PBD is often associated with polymicrobial infections containing resistant microorganisms (27), prophylactic antibiotics cover only $30 \%$ of these biliary pathogens (28). Given these studies, we hypothesized that the increased chance of bile contamination in the abdominal cavity would also increase the incidence of SSIs, especially organ/space SSIs.

In the present study, BE time was newly defined as an index of bile exposure to the peritoneal cavity during pancreaticoduodenectomy. To our knowledge, this is the first study that focuses on the relationship between BE time during pancreaticoduodenectomy and postoperative occurrence of organ/space SSI. Regarding the texture of the pancreas, soft pancreas has been a known risk factor for organ/space SSIs
Table IV. Independent factors for organ/space surgical site infection (SSI) occurrence as determined via multivariate analysis.

\begin{tabular}{lcrcc}
\hline Factor & Category & OR & $95 \%$ CI & $p$-Value \\
\hline Pancreatic texture & Soft & 16.5 & $1.923-141.391$ & 0.0106 \\
BE time group & $\geq 153 \mathrm{~min}$ & 4.8 & $1.232-19.264$ & 0.0240 \\
\hline
\end{tabular}

OR, Odds ratio; CI, confidence interval; $\mathrm{BE}$, bile exposure.

(7, 17-19, 29-31). However, it was interesting that even after excluding the effects of soft pancreatic textures, BE time remained an independent factor. This indicates that shortening $\mathrm{BE}$ time is expected to decrease organ/space SSI occurrence, regardless of pancreatic texture. In the current study, cut-off value of BE time (153 min) was optimal and our approach for predicting organ/space SSI occurrence was very practical.

The bacterial contamination of the abdominal cavity at the end of surgery is related to the subsequent development of 
post-pancreaticoduodenectomy SSIs (1). Large-volume peritoneal lavage has been recommended to remove bacteria in order to prevent SSI (32). These reports suggest that making efforts in reducing bacterial contamination during surgery is effective in preventing organ/space SSI development. Based on the current study, reduction of $\mathrm{BE}$ time may reduce the chances of organ/space SSIs by reducing bile contamination. Performing biliary reconstruction promptly after bile duct division during pancreaticoduodenectomy is a reasonable and practical method for reducing the chance of biliary infection. Additionally, whether large-volume peritoneal lavage at the end of surgery can reduce the incidence of bacterial contamination is an issue that may warrant further investigation. The limitations of the current study, include a small sample size, retrospective study, and a single center study.

In conclusion, long BE time is an independent risk factor for post-pancreaticoduodenectomy organ/space SSIs, and shortening BE time may reduce organ/space SSI occurrence.

\section{Conflicts of Interest}

The authors declare that there are no conflicts of interest regarding this study.

\section{Author's Contributions}

YK, SF, YI, KF and KY participated in literature research and drafting the manuscript. SF, HK, TM, YK, TH and TM participated in treating patients. TM and YK participated in analyzing the study data. All authors have read and approved of the final manuscript.

\section{Acknowledgements}

The Authors would like to thank Editage (www.editage.jp) for English language editing.

\section{References}

1 Sugiura T, Mizuno T, Okamura Y, Ito T, Yamamoto Y, Kawamura I, Kurai $\mathrm{H}$ and Uesaka $\mathrm{K}$ : Impact of bacterial contamination of the abdominal cavity during pancreaticoduodenectomy on surgical-site infection. Br J Surg 102(12): 1561-1566, 2015. PMID: 26206386. DOI: 10.1002/bjs.9899

2 Sugiura T, Uesaka K, Ohmagari N, Kanemoto H and Mizuno T: Risk factor of surgical site infection after pancreaticoduodenectomy. World J Surg 36(12): 2888-2894, 2012. PMID: 22907393. DOI: $10.1007 / \mathrm{s} 00268-012-1742-6$

3 Kimura W, Miyata H, Gotoh M, Hirai I, Kenjo A, Kitagawa Y, Shimada M, Baba H, Tomita N, Nakagoe T, Sugihara K and Mori M: A pancreaticoduodenectomy risk model derived from 8575 cases from a national single-race population (Japanese) using a web-based data entry system: The 30-day and in-hospital mortality rates for pancreaticoduodenectomy. Ann Surg 259(4): 773-780, 2014. PMID: 24253151. DOI: 10.1097/SLA.0000000 000000263
4 Adam U, Makowiec F, Riediger H, Schareck WD, Benz S and Hopt UT: Risk factors or complications after pancreatic head resection. Am J Surg 187(2): 201-208, 2004. PMID: 14769305. DOI: $10.1016 /$ j.amjsurg.2003.11.004

5 Schmidt CM, Powell ES, Yiannoutsos CT, Howard TJ, Wiebke EA, Wiesenauer CA, Baumgardner JA, Cummings OW, Jacobson LE, Broadie TA, Canal DF, Goulet RJ Jr., Curie EA, Cardenes H, Watkins JM, Loehrer PJ, Lillemoe KD and Madura JA: Pancreaticoduodenectomy: A 20-year experience in 516 patients. Arch Surg 139(7): 718-725; discussion 725-717, 2004. PMID: 15249403. DOI: 10.1001/archsurg.139.7.718

6 Takahashi Y, Takesue Y, Fujiwara M, Tatsumi S, Ichiki K, Fujimoto $\mathrm{J}$ and Kimura T: Risk factors for surgical site infection after major hepatobiliary and pancreatic surgery. J Infect Chemother 24(9): 739-743, 2018. PMID: 30001844. DOI: 10.1016/j.jiac.2018.05.007

7 De Pastena M, Paiella S, Marchegiani G, Malleo G, Ciprani D, Gasparini C, Secchettin E, Salvia R and Bassi C: Postoperative infections represent a major determinant of outcome after pancreaticoduodenectomy: Results from a high-volume center. Surgery 162(4): 792-801, 2017. PMID: 28676333. DOI: 10.1016/j.surg.2017.05.016

8 Fadayomi AB, Kasumova GG, Tabatabaie O, de Geus SWL, Kent TS, Ng SC, Moser AJ, Callery MP, Ashley SW and Tseng JF: Unique predictors and economic burden of superficial and deep/organ space surgical site infections following pancreatectomy. HPB (Oxford) 20(7): 658-668, 2018.PMID: 29526467. DOI: 10.1016/j.hpb.2018.01.008

9 Elliott IA, Chan C, Russell TA, Dann AM, Williams JL, Damato L, Chung H, Girgis MD, Hines OJ, Reber HA and Donahue TR: Distinction of risk factors for superficial $v s$ organ-space surgical site infections after pancreatic surgery. JAMA Surg 152(11): 1023-1029, 2017. PMID: 28700780. DOI: 10.1001/jamasurg. 2017.2155

10 Mussle B, Hempel S, Kahlert C, Distler M, Weitz J and Welsch T: Prognostic impact of bacterobilia on morbidity and postoperative management after pancreatoduodenectomy: A systematic review and meta-analysis. World J Surg 42(9): 29512962, 2018. PMID: 29464345. DOI: 10.1007/s00268-018-4546-5

11 Isla AM, Griniatsos J, Riaz A, Karvounis E and Williamson RC: Pancreaticoduodenectomy for periampullary malignancies: The effect of bile colonization on the postoperative outcome. Langenbecks Arch Surg 392(1): 67-73, 2007. PMID: 17089176. DOI: $10.1007 / \mathrm{s} 00423-006-0102-0$

12 Herzog T, Belyaev O, Muller CA, Mittelkotter U, Seelig MH, Weyhe D, Felderbauer P, Schlottmann R, Schrader H, Schmidt WE and Uhl W: Bacteribilia after preoperative bile duct stenting: A prospective study. J Clin Gastroenterol 43(5): 457-462, 2009. PMID: 19276992. DOI: 10.1097/MCG.0b013e318186b19b

13 Matsumoto M, Nakabayashi Y, Fujiwara Y, Funamizu N, Noaki R, Eto S, Sugano H, Otsuka M and Yanaga K: Duration of preoperative biliary drainage as a prognostic factor after pancreaticoduodenectomy for pancreatic head cancer. Antican Res 37(6): 3215-3219, 2017. PMID: 28551667. DOI: 10.21873/ anticanres. 11683

14 Gavazzi F, Ridolfi C, Capretti G, Angiolini MR, Morelli P, Casari E, Montorsi M and Zerbi A: Role of preoperative biliary stents, bile contamination and antibiotic prophylaxis in surgical site infections after pancreaticoduodenectomy. BMC Gastroenterol 16: 43, 2016. PMID: 27036376. DOI: 10.1186/s12876-016-0460-1 
15 Cortes A, Sauvanet A, Bert F, Janny S, Sockeel P, Kianmanesh R, Ponsot P, Ruszniewski P and Belghiti J: Effect of bile contamination on immediate outcomes after pancreaticoduodenectomy for tumor. J Am Coll Surg 202(1): 93-99, 2006. PMID: 16377502. DOI: 10.1016/j.jamcollsurg.2005.09.006

16 di Mola FF, Tavano F, Rago RR, De Bonis A, Valvano MR, Andriulli A and di Sebastiano P: Influence of preoperative biliary drainage on surgical outcome after pancreaticoduodenectomy: Single centre experience. Langenbecks Arch Surg 399(5): 649-657, 2014. PMID: 24682374. DOI: 10.1007/s00423-014-1184-8

17 Limongelli P, Pai M, Bansi D, Thiallinagram A, Tait P, Jackson J, Habib NA, Williamson RC and Jiao LR: Correlation between preoperative biliary drainage, bile duct contamination, and postoperative outcomes for pancreatic surgery. Surgery $142(3)$ : 313-318, 2007. PMID:17723881. DOI:10.1016/j.surg.2007.04.022

18 Ohgi K, Sugiura T, Yamamoto Y, Okamura Y, Ito T and Uesaka K: Bacterobilia may trigger the development and severity of pancreatic fistula after pancreatoduodenectomy. Surgery $160(3)$ : 725-730, 2016. PMID: 27233637. DOI:10.1016/j.surg.2016.03.032

19 Horan TC, Gaynes RP, Martone WJ, Jarvis WR and Emori TG: CDC definitions of nosocomial surgical site infections, 1992: A modification of cdc definitions of surgical wound infections. Infect Control Hosp Epidemiol 13(10): 606-608, 1992. PMID: 1334988.

20 Coppa GF and Eng K: Factors involved in antibiotic selection in elective colon and rectal surgery. Surgery 104(5): 853-858, 1988. PMID: 3055394

21 Kaiser AB, Herrington JL Jr., Jacobs JK, Mulherin JL Jr., Roach $\mathrm{AC}$ and Sawyers JL: Cefoxitin versus erythromycin, neomycin, and cefazolin in colorectal operations. Importance of the duration of the surgical procedure. Ann Surg 198(4): 525-530, 1983. PMID: 6354113. DOI: 10.1097/00000658-19831000000012

22 van der Gaag NA, Rauws EA, van Eijck CH, Bruno MJ, van der Harst E, Kubben FJ, Gerritsen JJ, Greve JW, Gerhards MF, de Hingh IH, Klinkenbijl JH, Nio CY, de Castro SM, Busch OR, van Gulik TM, Bossuyt PM and Gouma DJ: Preoperative biliary drainage for cancer of the head of the pancreas. N Engl J Med 362(2): 129-137, 2010. PMID: 20699038.

23 Jagannath P, Dhir V, Shrikhande S, Shah RC, Mullerpatan P and Mohandas KM: Effect of preoperative biliary stenting on immediate outcome after pancreaticoduodenectomy. Br J Surg 92(3): 356-361, 2005. PMID: 15672425. DOI: 10.1002/bjs.4864

24 Karsten TM, Allema JH, Reinders M, van Gulik TM, de Wit LT, Verbeek PC, Huibregtse K, Tytgat GN and Gouma DJ: Preoperative biliary drainage, colonisation of bile and postoperative complications in patients with tumours of the pancreatic head: A retrospective analysis of 241 consecutive patients. Eur J Surg 162(11): 881-888, 1996. PMID: 8956957.
25 Povoski SP, Karpeh MS Jr., Conlon KC, Blumgart LH and Brennan MF: Association of preoperative biliary drainage with postoperative outcome following pancreaticoduodenectomy. Ann Surg 230(2): 131-142, 1999. PMID: 10450725. DOI: 10.1097/ 00000658-199908000-00001

26 Shigeta H, Nagino M, Kamiya J, Uesaka K, Sano T, Yamamoto H, Hayakawa N, Kanai $M$ and Nimura $Y$ : Bacteremia after hepatectomy: An analysis of a single-center, 10-year experience with 407 patients. Langenbecks Arch Surg 387(3-4): 117-124, 2002. PMID: 12172855 . DOI: 10.1007/s00423-002-0301-2

27 Herzog T, Belyaev O, Hessam S, Suelberg D, Janot M, Schrader $\mathrm{H}$, Schmidt WE, Anders A, Uhl W and Mueller CA: Bacteribilia with resistant microorganisms after preoperative biliary drainage - the influence of bacteria on postoperative outcome. Scand J Gastroenterol 47(7): 827-835, 2012. PMID: 22507076. DOI: $10.3109 / 00365521.2012 .679684$

28 Sudo T, Murakami Y, Uemura K, Hayashidani Y, Hashimoto Y, Ohge $\mathrm{H}$ and Sueda T: Specific antibiotic prophylaxis based on bile cultures is required to prevent postoperative infectious complications in pancreatoduodenectomy patients who have undergone preoperative biliary drainage. World J Surg 31(11): 2230-2235, 2007. PMID: 17726628. DOI: 10.1007/s00268-0079210-4

29 Okano K, Hirao T, Unno M, Fujii T, Yoshitomi H, Suzuki S, Satoi S, Takahashi S, Kainuma O and Suzuki Y: Postoperative infectious complications after pancreatic resection. Br J Surg 102(12): 1551-1560, 2015. PMID: 26387569. DOI: 10.1002/ bjs. 9919

$30 \mathrm{Su}$ Z, Koga R, Saiura A, Natori T, Yamaguchi T and Yamamoto J: Factors influencing infectious complications after pancreatoduodenectomy. J Hepatobiliary Pancreat Sci 17(2): 174-179, 2010. PMID: 19517055. DOI: 10.1007/s00534-009-0128-0

31 Kent TS, Sachs TE, Callery MP and Vollmer CM Jr.: The burden of infection for elective pancreatic resections. Surgery 153(1): 8694, 2013. PMID: 22698935. DOI: 10.1016/j.surg.2012.03.026

32 Sugimoto K, Hirata M, Takishima T, Ohwada T, Shimazu S and Kakita A: Mechanically assisted intraoperative peritoneal lavage for generalized peritonitis as a result of perforation of the upper part of the gastrointestinal tract. J Am Coll Surg 179(4): 443448, 1994. PMID: 7921395.
Received June 5, 2019

Revised June 28, 2019

Accepted July 4, 2019 